\title{
Epilogue: \\ Continuous Movement
}

May 2008: I am in Los Angeles visiting Wesley Days. Before his class on capoeira and facilitation, I wander through the University's campus where I discover yet another checkpoint scene. A Palestinian student coalition has set up this mobile scenario; it is, in my estimation, a crude and excessive representation. The 'guards' here bear their guns menacingly, waving them in the faces of submissive 'Palestinians', reiterating an extreme projection of the oppressor/ oppressed narrative that limits transformation. Yet I find myself defending the image when a witnessing student contests it: 'That's not what happens. The soldiers don't hold their guns in your face like gangsters.' I get caught up in his provocation, the need to prove my own (limited) experiential knowledge. 'Yes, they do. Sometimes they do. I've been there.' And I have, but I have not seen anything like this image. I just combat his energy with a rebuttal. We argue back and forth, rooting our point of view in fragmented experiences and narrow ideology.

Then the checkpoint moves, and the student touches my arm, 'Let's keep talking. Let's move with them.' Our fight transforms into serious play, a game, a dance, and we become more flexible. We move through campus, in conversation and then in dialogue. I share what I know of Chen's story, how he discovered himself living a contradiction. The student speaks of the trials of his Iranian Jewish American family. Like me, he has not actually lived in Israel nor served in the IDF. We are proxies of an oppositional conflict, beginning our unfacilitated encounter by holding the ghost roles of The Israelis and The Palestinians as imagined opponents. But we keep moving. He confesses that he is in favor of ending the occupation. I listen more intimately to his hesitations. We started at the wrong place. But we were engaged through the theatrical image as a catalyst, and it led us towards a different kind of encounter. And we were both transformed by its conclusion. 